\title{
Numerical Model to Calculate Magnetization AC Losses for Superconducting Strip used for Current Transport Applications in Electric Aircrafts
}

\author{
Ashish Agrawal, Abhinav Kumar
}

\begin{abstract}
High Temperature Superconducting (HTS) tapes are being proposed in the current transportation applications in electric aircrafts due to their capacities to carry large currents with low losses and higher efficiencies. Many systems are involved in the aircraft power distribution units and each component has its own magnetic field which may affect the working of surrounding systems. It has been found from many studies that perpendicular field has significant effect on the critical current of the HTS tape. In the present study, effort has been made to develop a numerical code through which magnetization AC losses due to external magnetic field are evaluated for YBCO superconductor. Calculated values are compared with Halse-Brandt model and it has been found that with the increase in the index value ' $n$ ', the results are approaching the Halse-Brandt model.
\end{abstract}

Keywords: AC Losses, Superconducting Strip, Current Transport, Numerical Modelling, Roebel Cables.

\section{INTRODUCTION}

High Temperature Superconducting (HTS) tapes find its applications in many engineering systems like high power transmission cables, superconducting fault current limiters, motors, generators, transformers and superconducting magnetic energy storage systems over the last few years. Scientists want to replace normal conductors with superconductors as they have almost zero losses compared to conventional conductors involved in many engineering applications. In this regard, NASA and AFRL have decided to use superconductors in the hybrid and fully electric aircrafts [1][2]. Generally, Roebel cables have been proposed by many researchers for the power transmission applications as its structural arrangement leads to fewer losses [3]-[8].

Electric aircrafts are going to be the future of aviation sector and many researchers are trying to make the technology feasible. The existing critical challenges that are delaying the technology are related with the energy or power availability and power transmission to the motors. The conceptual design of fully electric aircraft N3-X and EADS VoltAir is shown in Fig. 1 where many superconducting sub-systems are involved

Revised Manuscript Received on December 05, 2019

* Correspondence Author

Ashish Agrawal, Department of Mechanical Engineering, Madanapalle Institute of Technology and Science, Madanapalle, India. Email: drashishagrawal@mits.ac.in

Abhinav Kumar*, School of Mechanical Engineering, Lovely Professional University, Phagwara, India. Email: drabhinav@ieee.org such as cables, motors, magnetic energy storage systems and fault current limiters to make sure a uninterrupted power distribution [9][10]. Other magnetic components like magnetic bearing are installed in the various parts of aircraft which has their own magnetic field and there may be situations where these fields can affect the performance of superconducting cables and other sub-systems. Many researchers have studied the effect of perpendicular external magnetic fields on the AC losses and critical current of the superconducting tape and they have found it has a significant effect on the system performance [11]-[15]. Therefore, in the present study, a numerical code has been developed to calculate the AC losses due to the existence of perpendicular magnetic field. The results are compared with Halse-Brandt exact solution and it has been found that with the increase in the n-value the numerical model is approaching the Halse-Brandt model [16] [17].

\section{NUMERICAL MODELLING}

A numerical model using Matlab has been developed for YBCO tape having specifications enlisted in Table I. The superconducting tape is modelled with E-J power law and Maxwell's equations have been used to solve the problem. A correlation for the magnetic vector potential has been derived for the current distribution where the electric field is related to the vector potential by a time derivative. Along with the E-J power law, this defines the current distribution in the tape. Numerical integration on current distribution equation has been used to evaluate the current as a function of time. Losses can be measured through the product of electric field and current density. The strip or tape used for the study is manufactured by SuperPower (SCS12050) whose critical current is $330 \mathrm{~A}$ at $77 \mathrm{~K}$ temperature. The magnetic vector potential at distance ' $r$ ' of an infinite wire carrying current $I$ can be calculated as [18]:

$\mathbf{A}=-\frac{\mu_{0} \mathbf{I}}{2 \pi} \ln (r)$

The vector potential at $\left(y_{i}, z_{i}\right)$ of a thin sheet having width dy' carrying $J_{j} d y^{\prime}$ is therefore, 


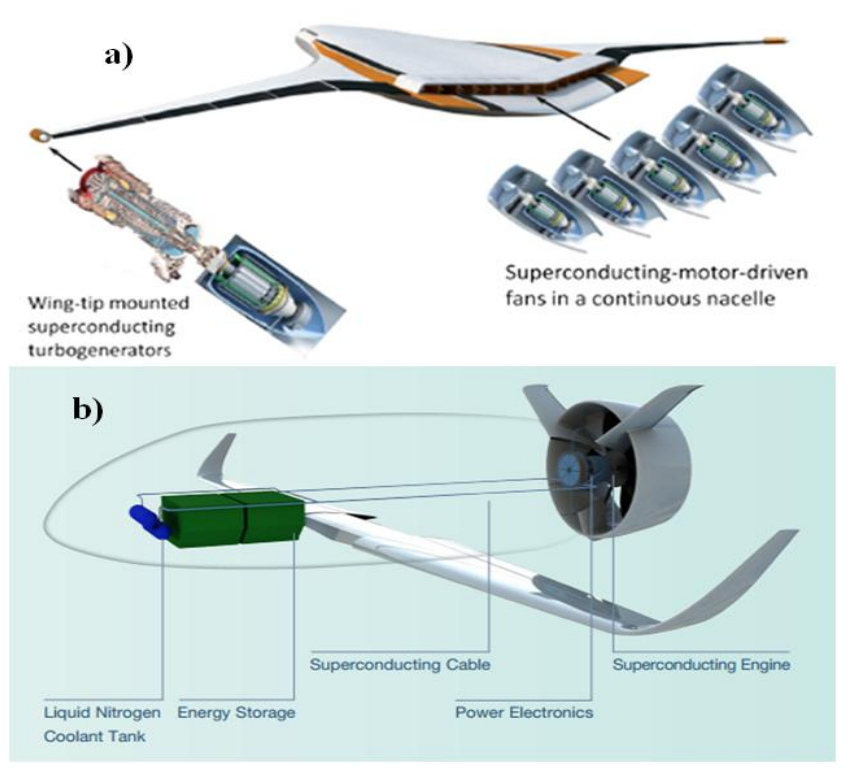

Fig. 1 Superconducting Machines in Electric aircrafts (a) N3-X, (b) EADS VoltAir

$$
\begin{aligned}
d A_{i j} & =-\frac{\mu_{0} J_{j}}{2 \pi} \ln \left(\sqrt{\left(y_{i}-y^{\prime}\right)^{2}+\left(z_{i}-z_{j}\right)^{2}}\right) d y^{\prime} \\
& =-\frac{\mu_{0} J_{j}}{4 \pi} \ln \left(\left(y_{i}-y^{\prime}\right)^{2}+\left(z_{i}-z_{j}\right)^{2}\right) d y^{\prime}
\end{aligned}
$$

The vector potential $A_{i j}$ can be calculated as:

$$
A_{i j}=-\frac{\mu_{0} J_{j}}{4 \pi} \int_{y_{L, j}}^{y_{R, j}} \ln \left(\left(y_{i}-y^{\prime}\right)^{2}+\left(z_{i}-z_{j}\right)^{2}\right) d y^{\prime}
$$

In order to get the vector potential of the entire cable $A_{i}$ at $\left(y_{i}, z_{i}\right)$, the contributions of all elements are sum up together:

$$
A_{i}=-\frac{\mu_{0}}{4 \pi} \sum J_{j} \int_{y_{L, j}}^{y_{R, j}} \ln \left(\left(y_{i}-y^{\prime}\right)^{2}+\left(z_{i}-z_{j}\right)^{2}\right) d y^{\prime}
$$

It can also be represented in current $J_{j}$ and a geometrical factor $K_{i j}$

$$
A_{i}=\frac{\mu_{0}}{4 \pi} \sum K_{i j} J_{j}
$$

where,

$$
\begin{gathered}
K_{i j}=-\frac{1}{2} \int_{y_{L, j}}^{y_{R, j}} \ln \left(\left(y_{i}-y^{\prime}\right)^{2}+\left(z_{i}-z_{j}\right)^{2}\right) d y^{\prime} \\
=\left(y_{i}-y_{R, j}\right)\left(\ln \left|y_{i}-y_{R, j}\right|-1\right) \\
-\left(y_{i}-y_{R, j}\right)\left(\ln \left|y_{i}-y_{R, j}\right|-1\right) \rightarrow z_{i}=z_{j}
\end{gathered}
$$

Since $K$ depends upon the geometry only, therefore it needs to be evaluated once and remains invariant with respect to time. For external magnetic field, the vector potential can be represented as:

$$
A_{e x t, x}(y, z)=-y B_{e x t, z}+z B_{e x t, y}
$$

Therefore, the total vector potential is

$$
\begin{aligned}
& A\left(y_{i}, z_{i}\right)=-y_{i} B_{e x t, z}+z_{i} B_{e x t, y}+\frac{\mu_{0}}{2 \pi} \sum_{j} K_{i j} J_{j} \\
& E=-\nabla V-\frac{\partial A}{\partial t}
\end{aligned}
$$

Vector potentials and external electric field in $\mathrm{x}$-direction can be described by $\mathrm{V}=-\mathrm{xE}_{\text {ext }, \mathrm{x}}$.

$$
\begin{gathered}
E_{i}(J)=-\frac{d V}{d x}-\frac{\partial}{\partial t}\left(A_{i}+A_{e x t, x}\left(y_{i}, z_{i}\right)\right) \\
=E_{e x t, x}-\frac{\mu_{0}}{2 \pi} \sum_{j} K_{i j} \dot{J}_{j}+y_{i} \dot{B}_{e x t, z}-z_{i} \dot{B}_{e x t, y} \\
\sum_{j} K_{i j} \dot{J}_{j}=\frac{2 \pi}{\mu_{0}}\left(E_{e x t, x}-E_{i}(J)+y_{i} \dot{B}_{e x t, z}-z_{i} \dot{B}_{e x t, y}\right) \\
\dot{J}_{j}=\frac{2 \pi}{\mu_{0}} \sum_{j} K_{i j}{ }^{-1}\left(E_{e x t, x}-E_{j}(J)+y_{j} \dot{B}_{e x t, z}-z_{j} \dot{B}_{e x t, y}\right) \\
E(J)=E_{c}\left(\frac{J}{J_{c}\left(B_{y}, B_{z}\right)}\right)^{n}
\end{gathered}
$$

Using $E(J)$ power law, this equation can be solved through Matlab and it represents the current distribution. Table I shows the strip parameter used for analysis.

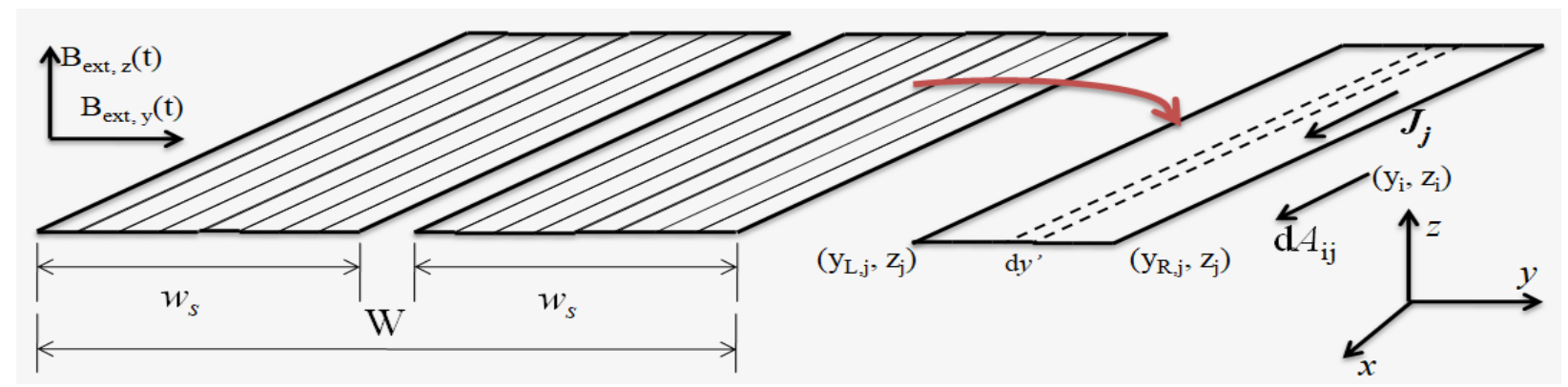

Fig. 2 Schematic of Roebel cable divided into thin sheets and current density is in $x$-direction

Fig. 3 to Fig. 6 describes the current distribution in the strip and it can be noticed that for normal conductor $(n=1)$ external field has significant effect on the current distribution compared to superconductor ( $\mathrm{n}=5$ to 30$)$ and this effect is decreased as the n-value increased. For comparison, from the
Fig. 3 it can be observed that the $Q$ value is $85.7 \mathrm{~J} / \mathrm{m} /$ cycle and $\mathrm{n}=30$ its value is $4.6 \mathrm{~J} / \mathrm{m} /$ cycle. 
Table- I: Strip Parameters

\begin{tabular}{|l|l|}
\hline Parameter & Value \\
\hline Strip Width & $0.012 \mathrm{~m}$ \\
\hline Critical current/Width & $27.5 \mathrm{e} 3 \mathrm{~A} / \mathrm{m}$ \\
\hline Critical Electric Field, $\mathrm{E}_{\mathrm{c}}$ & $1 \mathrm{e}-4$ \\
\hline n-value & 1 to 30 \\
\hline
\end{tabular}

\section{AC LOSSES}

AC losses have been calculated for an ideally superconducting thin strip with an n-value approaching 30 . For comparison, the results are compared with the exact solution derived by Halse [16] and later by Brandt and Indenbom [17]:
$Q=\frac{2 \mu_{0} J_{c}^{2} w^{2}}{\pi}\left[\ln \left(\cosh \left(\frac{\pi H_{0}}{J_{c}}\right)\right)-\frac{\pi H_{0}}{J_{c}} \tanh \left(\frac{\pi H_{0}}{J_{c}}\right)\right]$

In the above equation, $H_{0}=B_{0} / \mu_{0}$ is the peak external magnetic field during the cycle. It can be observed that the numerical calculated losses for various n-values are approaching to ideal superconducting strip losses as the n-value increasing. Fig. 7 shows the magnetization AC losses per cycle and Fig. 8 describes the normalized losses per cycle. Normalization is done with $B_{0}^{2}$ in order to observe the variation clearly and it can be observed that with the increase in the n-value the losses are approaching to the ideal superconducting behavior. Similar results can be found into study done by J. Otten [18].

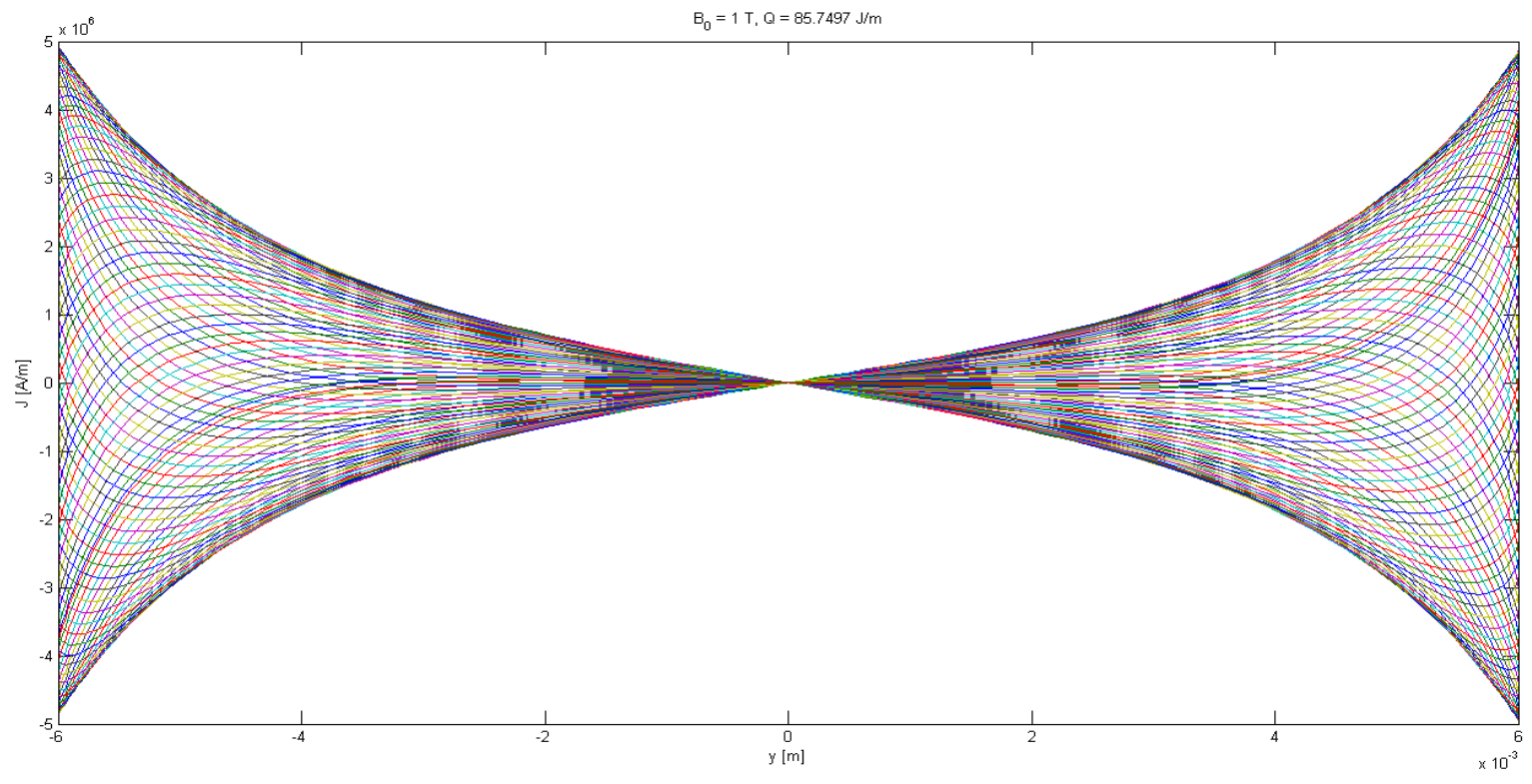

Fig. 3 Current distribution for normal conductor i.e. $n=1$

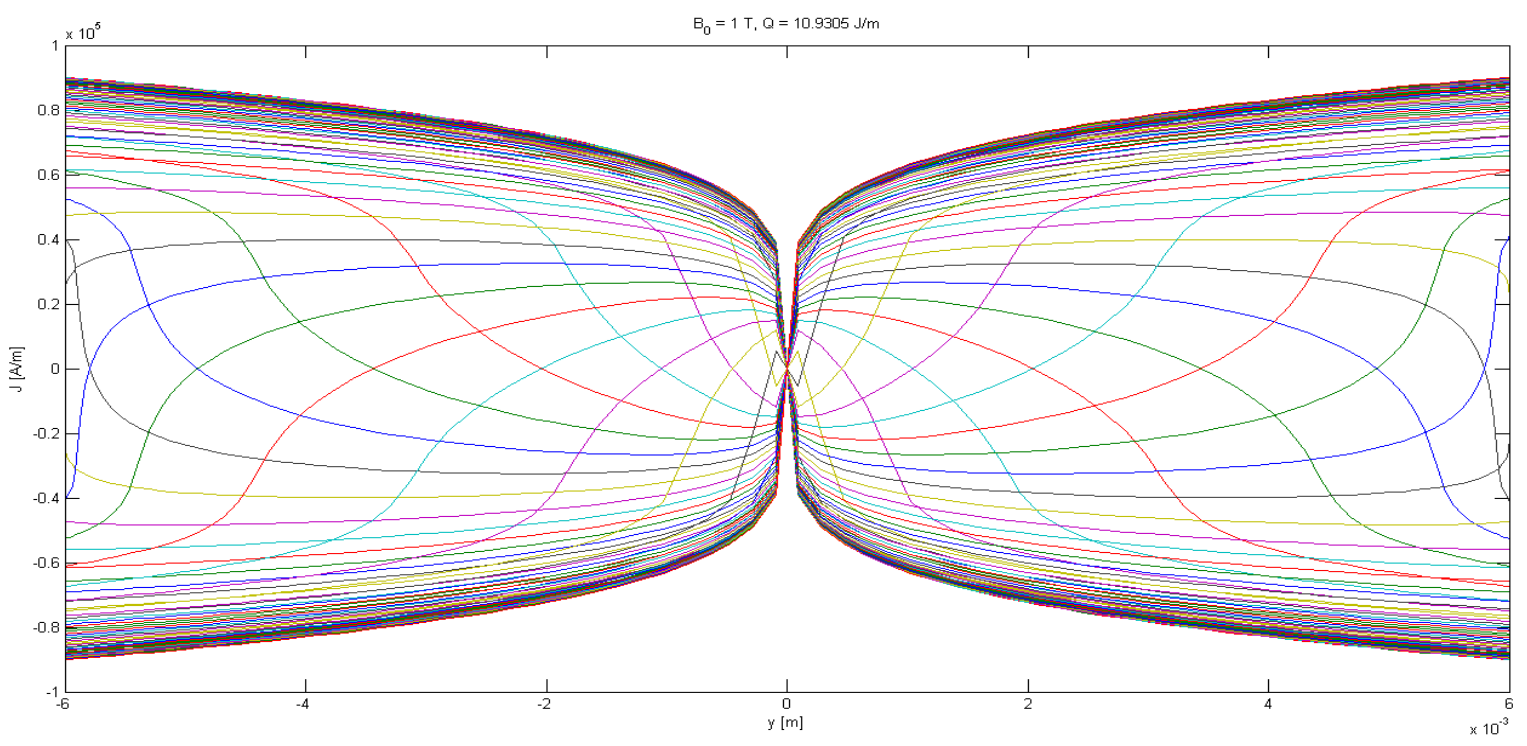

Fig. 4 Current distribution for Superconductor i.e. $n=5$ 


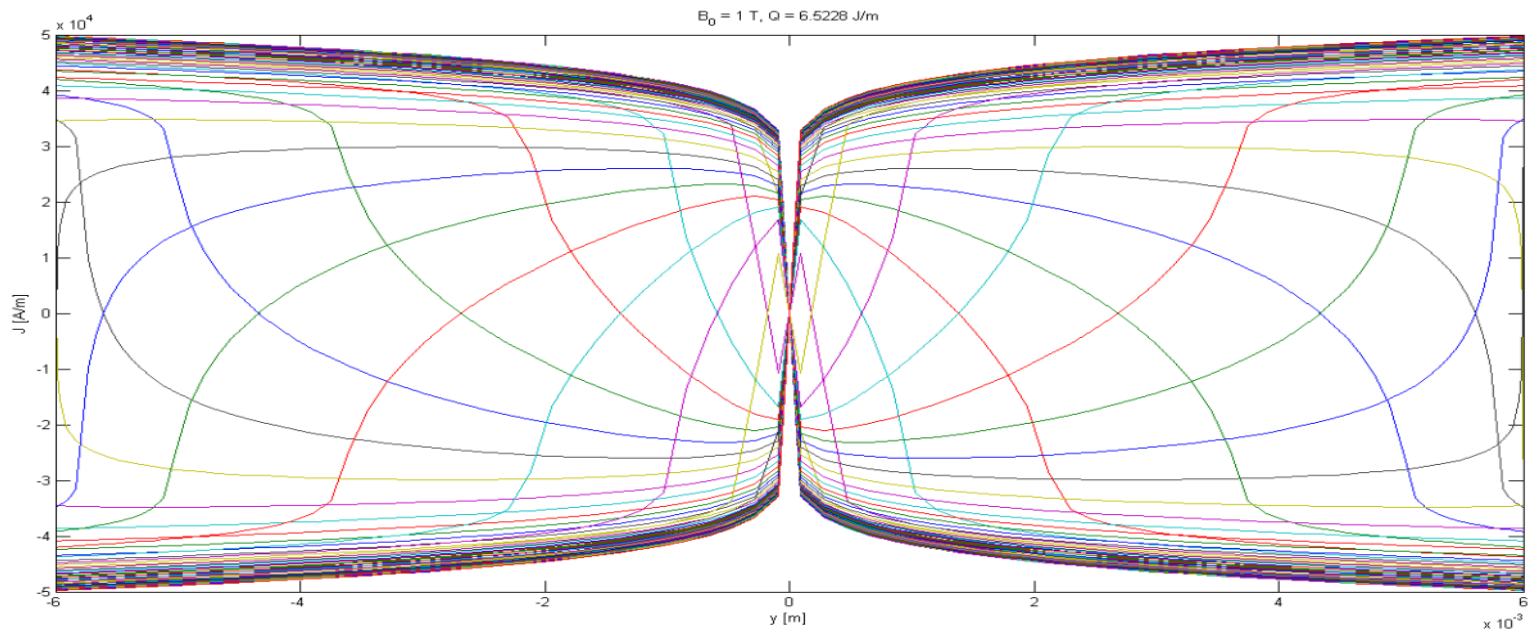

Fig. 5 Current distribution for Superconductor i.e. $n=10$

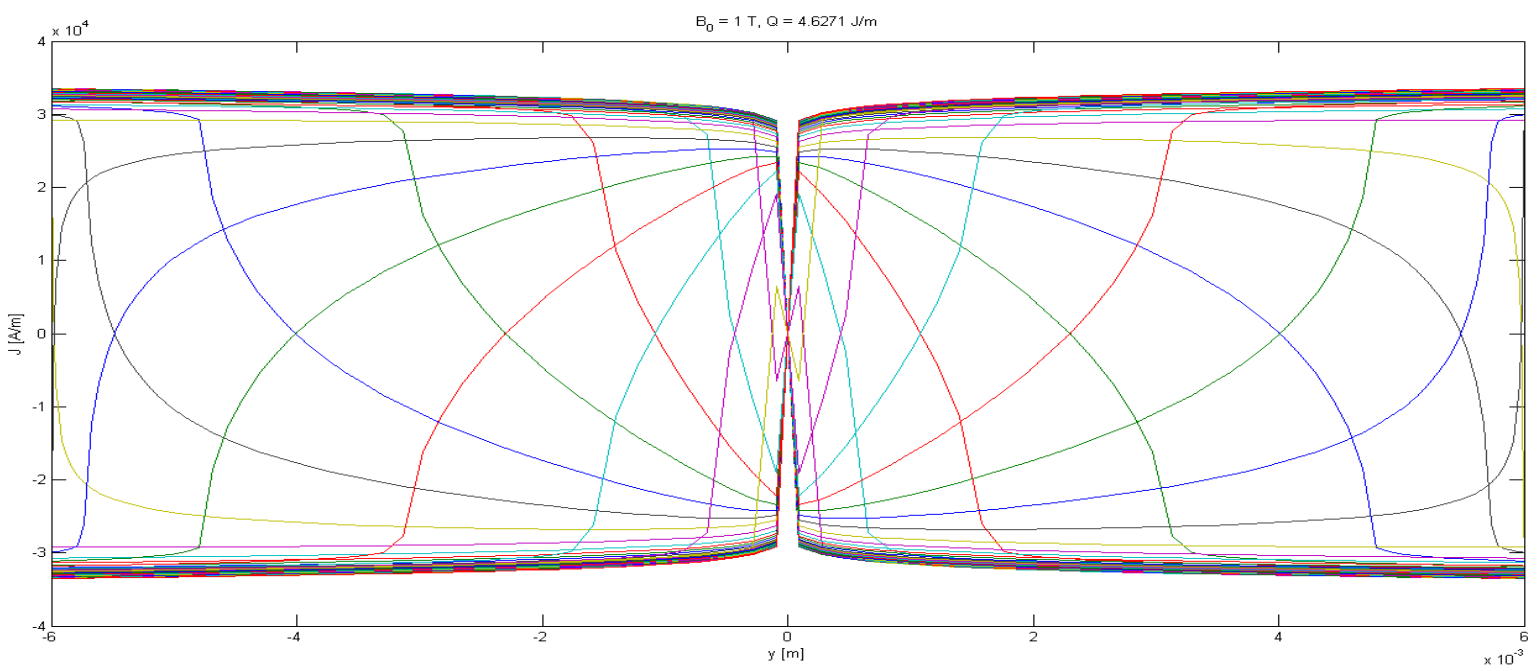

Fig. 6 Current distribution for Superconductor i.e. $n=30$

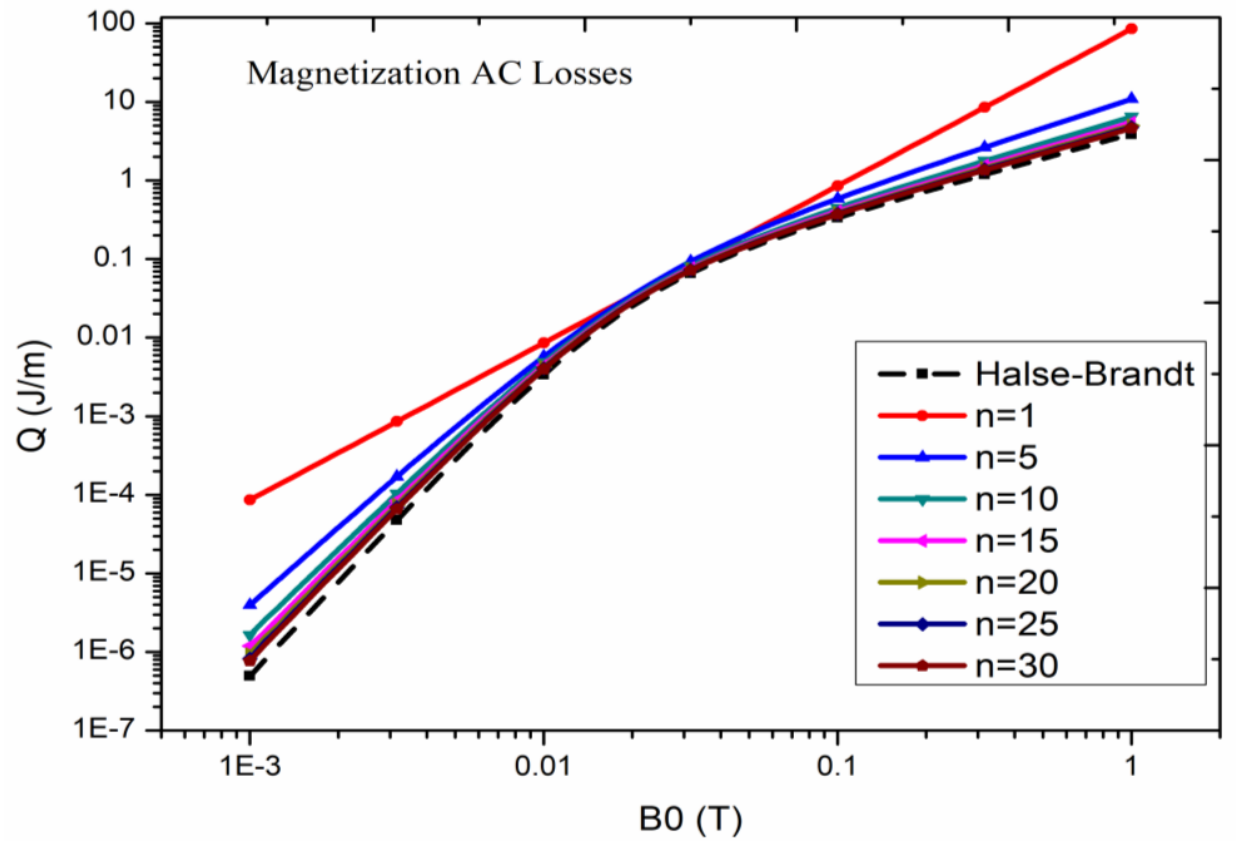

Fig. 7 Magnetization AC losses for numeric and Halse-Brandt 


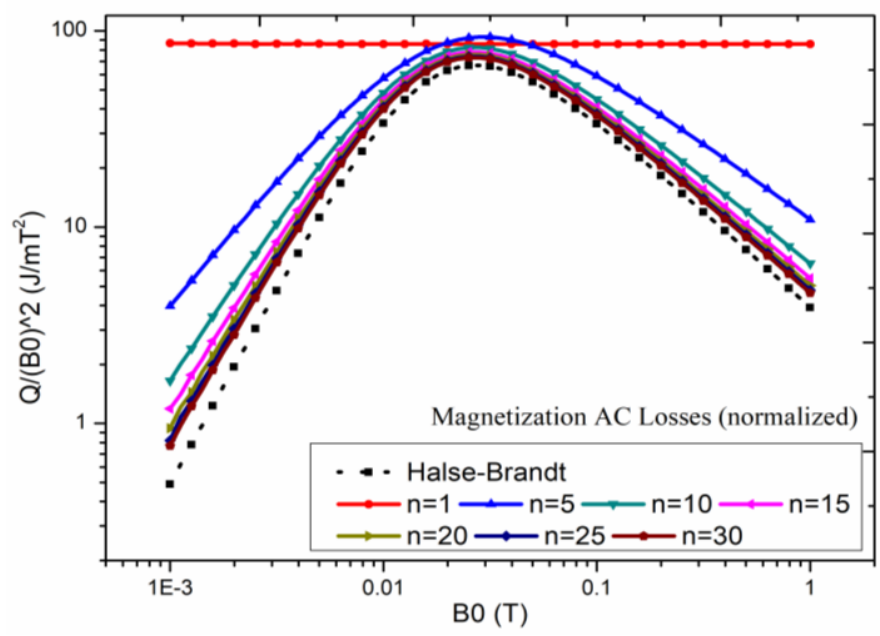

Fig. 8 Normalized Magnetization AC losses for numeric and Halse-Brandt

\section{CONCLUSION}

A numerical model using Matlab has been developed to calculate the magnetization AC losses due to external field. The simulations are done for one cycle and the study reveals that the higher n-values can result into lower losses. Therefore, while designing the cables or aircraft power system one should try to have a superconductor with high n-value.

\section{REFERENCES}

1. S. C. Clarke, "Aircraft Electric Propulsion Systems: Applied Research at NASA," pp. 1-37, 2015.

2. T. J. Haugan, "Development of Superconducting and Cryogenic Power Systems and Impact for Aircraft Propulsion," Air Force Res. Lab., no. April, 2015

3. S. S. Fetisov et al., "Development and Characterization of a $2 \mathrm{G}$ HTS Roebel Cable for Aircraft Power Systems," IEEE Trans. Appl. Supercond., vol. 26, no. 3, pp. 1-4, 2016.

4. A. Kario, M. Vojenciak, A. Kling, B. Ringsdorf, A. Jung, and W. Goldacker, "Superconducting properties of Roebel coated conductor cable from Superpower and SuperOx tapes with different transposition length," in International Workshop on Coated Conductors Applications-CCA2014, Jeju, Korea, 2014, vol. 30.

5. S. Lee et al., "Development and production of second generation high Tc superconducting tapes at SuperOx and first tests of model cables," Supercond. Sci. Technol., vol. 27, no. 4, p. 44022, 2014.

6. M. Solovyov, J. Šouc, and F. Gömöry, "AC loss properties of single-layer CORC cables," in Journal of Physics: Conference Series, 2014, vol. 507, no. 2, p. 22034.

7. S. Elschner et al., "New experimental method for investigating AC losses in concentric HTS power cables," IEEE Trans. Appl. Supercond., vol. 25, no. 3, pp. 1-5, 2014.

8. T. Yamaguchi, Y. Shingai, M. Konishi, M. Ohya, Y. Ashibe, and H. Yumura, "Large current and low AC loss high temperature superconducting power cable using REBCO wires," SEI Tech. Rev., vol. 78, p. 79, 2014.

9. K. Davies, P. Norman, C. Jones, S. Galloway, and M. Husband, "A review of Turboelectric Distributed Propulsion technologies for N+3 aircraft electrical systems," in 2013 48th International Universities' Power Engineering Conference (UPEC), 2013, pp. 1-5.

10. H. Alafnan et al., "Application of SMES-FCL in Electric Aircraft for Stability Improvement," IEEE Trans. Appl. Supercond., vol. 29, no. 5, pp. 1-6, 2019 .

11. Y. Sogabe, M. Nii, T. Tsukamoto, T. Nakamura, and N. Amemiya, "Electromagnetic Field Analyses of REBCO Roebel Cables Wound into Coil Configurations," IEEE Trans. Appl. Supercond., vol. 24, no. 3, pp. $1-5,2014$.

12. T. Tsukamoto, T. Mifune, Y. Sogabe, Z. Jiang, T. Nakamura, and N. Amemiya, "Influence of Geometrical Configurations of HTS Roebel
Cables on Their AC Losses," IEEE Trans. Appl. Supercond., vol. 25, no. 3 , pp. 1-5, 2015.

13. L. S. Lakshmi et al., "Magnetic and Transport AC Losses in HTS Roebel Cable," IEEE Trans. Appl. Supercond., vol. 21, no. 3, pp. 3311-3315, 2011.

14. T. Komeda et al., "Experimental Comparison of AC Loss in REBCO Roebel Cables Consisting of Six Strands and Ten Strands," IEEE Trans Appl. Supercond., vol. 24, no. 3, pp. 1-5, 2014.

15. Z. Jiang et al., "Transport AC Loss Characteristics of a Five Strand YBCO Roebel Cable With Magnetic Substrate," IEEE Trans. Appl. Supercond., vol. 21, no. 3, pp. 3289-3292, 2011.

16. M. R. Halse, "AC face field losses in a type II superconductor," J. Phys. D. Appl. Phys., vol. 3, no. 5, p. 717, 1970.

17. E. H. Brandt and M. Indenbom, "Type-II-superconductor strip with current in a perpendicular magnetic field," Phys. Rev. B, vol. 48, no. 17, p. 12893, 1993.

18. S. J. Otten, Characterisation of REBCO Roebel cables, vol. 24. KIT Scientific Publishing, 2019.

\section{AUTHORS PROFILE}

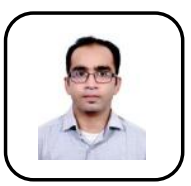

Dr. Ashish Agrawal is an Assistant Professor at the Department of Mechanical Engineering in Madanapalle Institute of Technology and Science in Madanapalle, Andhra Pradesh in India. He obtained his Masters and $\mathrm{PhD}$ from Indian Institute of Technology, Kanpur in 2010 and 2017 respectively. He graduated in Mechanica Engineering from Madhav Institute of Technology and Science in Gwalior, Madhya Pradesh in India. Prior joining to MITS Madanapalle, he has worked as an Assistant Professor at Lovely Professional University in Punjab. Broadly his research interests lie in computational and experimental heat transfer and fluid dynamics. More specifically, his research sears include heat transfer in rotary kilns, electronics cooling, superconducting magnetic energy storage system and vortex tube cooling system.

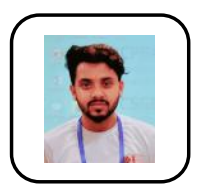

Abhinav Kumar is pursuing his Doctorate in Mechanical Engineering from Lovely Professional University, Punjab, India. He has completed his master's in thermal engineering specialization from Lovely Professional University in 2014 and bachelor's in Mechanical Engineering from Punjab Technical University in 2011. He has published many SCI and Scopus indexed articles in various journals and has attended many international conferences. His area of research is vast including superconducting magnetic energy storage systems, superconducting fault current limiters, high temperature superconducting cable design \& cooling, cryogenic fluid properties, nozzle cooling, computational fluid dynamics and solar energy storage systems. $\mathrm{He}$ is one of the reviewers for SCI and Scopus indexed journals and conferences. $\mathrm{He}$ has been awarded with University Academic Honor and University Honor Roll for his excellent academic records. He is holding Student IEEE and life membership of Indian Society of Heat and Mass Transfer (ISHMT). 